\title{
Insight from ozone and water vapour on transport in the tropical tropopause layer (TTL)
}

\author{
F. Ploeger ${ }^{1}$, S. Fueglistaler ${ }^{5}$, J.-U. Grooß ${ }^{1}$, G. Günther ${ }^{1}$, P. Konopka ${ }^{1}$, Y.S. Liu ${ }^{2}$, R. Müller ${ }^{1}$, F. Ravegnani ${ }^{4}$, \\ C. Schiller ${ }^{1}$, A. Ulanovski ${ }^{3}$, and M. Riese ${ }^{1}$ \\ ${ }^{1}$ Institute for Chemistry and Dynamics of the Geosphere (ICG-1), Forschungszentrum Jülich, Jülich, Germany \\ ${ }^{2}$ Applied Mathematics and Theoretical Physics, University of Cambridge, Cambridge, UK \\ ${ }^{3} \mathrm{CAO}$, Dolgoprudny, Russia \\ ${ }^{4}$ Institute of Atmospheric Sciences and Climate, ISAC-CNR, Bologna, Italy \\ ${ }^{5}$ Dept. of Geosciences, Princeton University, Princeton, NJ, USA
}

Received: 25 August 2010 - Published in Atmos. Chem. Phys. Discuss.: 1 October 2010

Revised: 22 December 2010 - Accepted: 5 January 2011 - Published: 14 January 2011

\begin{abstract}
We explore the potential of ozone observations to constrain transport processes in the tropical tropopause layer (TTL), and contrast it with insights that can be obtained from water vapour. Global fields from Halogen Occultation Experiment (HALOE) and in-situ observations are predicted using a backtrajectory approach that captures advection, instantaneous freeze-drying and photolytical ozone production. Two different representations of transport (kinematic and diabatic 3-month backtrajectories based on ERAInterim data) are used to evaluate the sensitivity to differences in transport. Results show that mean profiles and seasonality of both tracers can be reasonably reconstructed. Water vapour predictions are similar for both transport representations, but predictions for ozone are systematically higher for kinematic transport. Compared to global HALOE observations, the diabatic model prediction underestimates the vertical ozone gradient. Comparison of the kinematic prediction with observations obtained during the tropical SCOUTO3 campaign shows a large high bias above $390 \mathrm{~K}$ potential temperature. We show that ozone predictions and vertical dispersion of the trajectories are highly correlated, rendering ozone an interesting tracer for aspects of transport to which water vapour is not sensitive. We show that dispersion and mean upwelling have similar effects on ozone profiles, with slower upwelling and larger dispersion both leading to higher ozone concentrations. Analyses of tropical upwelling based
\end{abstract}

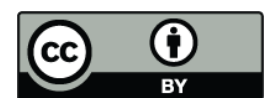

Correspondence to: F. Ploeger (f.ploeger@fz-juelich.de) on mean transport characteristics, and model validation have to take into account this ambiguity between tropical ozone production and in-mixing from the stratosphere. In turn, ozone provides constraints on transport in the TTL and lower stratosphere that cannot be obtained from water vapour.

\section{Introduction}

The tropical tropopause layer (TTL) plays an important role for climate, as changes therein due to increasing greenhouse gases may affect troposphere-stratosphere exchange of radiatively active trace gases (Highwood and Hoskins, 1998; Gettelman and Forster, 2002; Fueglistaler et al., 2009a). However, the relative importance of different transport processes in the TTL such as deep convection, large-scale upwelling, and horizontal exchange with the extratropics remains a matter of debate. Chemistry Climate Models and Chemical Transport Models are suitable tools to understand and quantify these processes. However, model validation is subject to uncertainties arising from ambiguities in the processes that control the model's dynamical and tracer fields. That is, two processes may have a similar impact on a model's tracer fields, and agreement with observations alone does not validate the model's particular choice of the parameterisation of the two processes.

Water vapour and ozone in the TTL are both controlled to leading order by relatively simple processes. For water vapour, the region of minimum temperatures around the tropical tropopause poses strong constraints on the amount of

Published by Copernicus Publications on behalf of the European Geosciences Union. 
water entering the stratosphere (Brewer, 1949; Holton and Gettelman, 2001; Bonazzola and Haynes, 2004; Fueglistaler et al., 2005). Also water vapour mixing ratios in the extratropical lowermost stratosphere are strongly related to tropical temperatures (compare the recent study of Hoor et al., 2010). For ozone, Avallone and Prather (1996) showed that in the tropical lower stratosphere the chemistry is dominated by ozone production from photolysis. Correspondingly, the annual cycle in lower stratospheric ozone concentrations has been linked to the annual cycle in upwelling of the stratospheric residual circulation (Randel et al., 2007), but seasonal variations in in-mixing of extratropical air masses may also play an important role (Konopka et al., 2009, 2010).

Here, we combine transport as represented by backtrajectories based on European Centre for Medium-Range Weather Forecasts (ECMWF) ERA-Interim data (Simmons et al., 2006; Uppala et al., 2008) with simple models of physical and chemical processes controlling water vapour and ozone. Fueglistaler et al. (2005) and Fueglistaler and Haynes (2005) showed that the mean, the annual cycle and interannual variability of water entering the stratosphere in the tropics can be reconstructed from trajectories, assuming that the lowest temperature in the backward history of an air parcel (here a trajectory) determines its water vapour mixing ratio. A similar approach was shown to give good agreement also with water vapour in-situ measurements in the TTL (Schiller et al., 2009). For ozone, trajectory reconstruction methods are less established. Previous work includes reconstructions of tropical ozone observations based on passive tracer transport (Legras et al., 2003; Pisso and Legras, 2008; James and Legras, 2009), and based on a simplified, one-dimensional trajectory approach (Konopka et al., 2009).

Here, we use the full 4-dimensional transport as given by trajectories to predict both the annual mean and the annual cycle of tropical mean ozone concentrations, and to predict ozone concentrations from in-situ measurements during the SCOUT-tropical aircraft campaign over Darwin/Australia (Brunner et al., 2009). We contrast results for ozone with the corresponding results for water vapour in order to address the following questions: (i) Can ozone in the TTL be predicted by photochemical production and transport based on trajectories, and how does the quality of the prediction compare with the results for water vapour? (ii) Which processes control TTL ozone concentrations in the model calculations? (iii) What can be learnt from ozone and water vapour predictions regarding transport in the TTL?

The paper is structured as follows. Section 2 provides a description of data and methods, and Sect. 3 shows the model predictions for water vapour and ozone, and comparison to observations. Section 4 discusses how transport affects ozone and water vapour model calculations, and Sect. 5 discusses the results, and how they affect conclusions from model validation and process studies.

\section{Data and method}

\subsection{Trajectory calculations}

We reconstruct water vapour and ozone from backtrajectories calculated with the Chemical Lagrangian Model of the Stratosphere (CLaMS) trajectory model (McKenna et al., 2002a,b; Konopka et al., 2007). Two different calculations for vertical transport (diabatic and kinematic) allow us to study the impact of differences in model transport on predicted tracer fields.

The diabatic trajectories refer to a transport representation with potential temperature $\theta$ as vertical coordinate. Crossisentropic vertical velocity $\dot{\theta}=d \theta / d t$ is taken from the forecast total diabatic heating rate, being the sum of all-sky radiative heating and all other diabatic heating terms, including latent heat release (see e.g., Fueglistaler et al., 2009b; Ploeger et al., 2010). Conversely, kinematic trajectories use the reanalysis vertical wind $\omega=d p / d t$ as vertical velocity. We use reanalysis data every six hours, with the heating rates interpolated from the nearest $6 \mathrm{~h}$ or $12 \mathrm{~h}$ forecasts. The $\omega$ wind provided by the ECMWF is calculated from the small residual between the large horizontal wind terms in the continuity equation, and it is known that the (instantaneous) $\omega$ field from analysed data is noisy, giving higher dispersion for kinematic trajectories than diabatic trajectories (e.g., Schoeberl et al., 2003; Wohltmann and Rex, 2008). Trajectory dispersion may depend on the sampling frequency of velocity fields (compare e.g., Pisso et al., 2010). Note that for ERAInterim used here, the differences in transport between diabatic and kinematic trajectories are smaller than for the older ERA-40 data (Liu et al., 2010), likely due to the 4D-Var assimilation in ERA-Interim (compare Monge-Sanz et al., 2007), but the differences are still detectable and significant as we will show below.

Trajectories are started on the 15th day of each month of the year 2002 in the tropical lower stratosphere on the $400 \mathrm{~K}$ potential temperature level on a regular grid with $1^{\circ} \times 1^{\circ}$ latitude/longitude spacing, between $\pm 20^{\circ}$ latitude, and are integrated backwards in time for 90 days. For the comparison with in-situ measurements during the tropical SCOUT-O3 campaign (Brunner et al., 2009), the trajectories are started along the research aircraft (M55 Geophysica) flight tracks every second and are integrated backwards in time for 60 days. We include all observations of both local and transfer flights equatorwards of $\pm 20^{\circ}$ latitude in our analysis, except for the two flights on 30 November 2005 (11 flights in total). During these two excluded flights a single deep convective storm was repeatedly probed and observations do not represent background TTL conditions.

Sensitivity to the length of the integration period has been evaluated by comparing results obtained from 5 month integration for the global fields, and 90 days for the comparison with in-situ measurements. In the following, we show results 


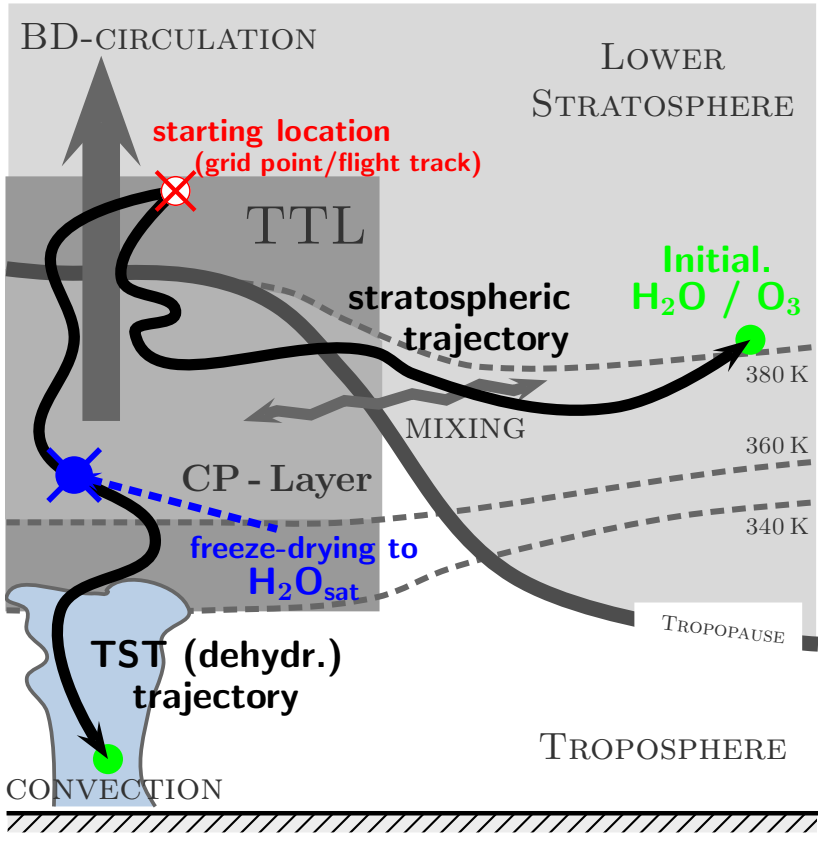

Fig. 1. Schematic of the method used in this paper (see text). The figure shows troposphere-to-stratosphere transport (TST trajectories) and purely stratospheric trajectories. The upwelling branch of the stratospheric Brewer-Dobson (BD) circulation is displayed as a thick grey arrow, quasi-horizontal stratosphere-troposphere exchange as a grey wavy arrow, particular isentropes as thin grey dashed, the tropopause as a grey solid line. The Cold Point (CP) layer between 360 and $380 \mathrm{~K}$ is coloured light-grey. The black arrows characterising typical TST and stratospheric backtrajectories point backwards in time. The red dot shows the starting location. Green dots illustrate the initialisation (locations) of backtrajectories with ECMWF (HALOE) water vapour and ozone at the end points. The blue dot illustrates the location where dehydration to the local minimum saturation water vapour mixing ratio $\left(\mathrm{H}_{2} \mathrm{O}_{\text {sat }}\right)$ occurs along the TST backtrajectory.

and conclusions only for those aspects of the calculations that are insensitive to trajectory length.

In order to facilitate the interpretation of results, we group the model predictions of water vapour and ozone according to the pathway of the trajectories, as illustrated in Fig. 1. The separation criterion is the minimum potential temperature encountered along the trajectory. The ensemble of trajectories that can be traced back to below $350 \mathrm{~K}$ potential temperature is called the "troposphere-to-stratosphere transport" (TST) ensemble (Fueglistaler et al., 2004), the remainder the "stratospheric" ensemble. Here, the choice of the $350 \mathrm{~K}$ value is not critical, a slightly different value (below the level of zero radiative heating around $355 \mathrm{~K}$ ) yields very similar results. The separation between TST and stratospheric trajectories proves useful because for the TST ensemble both water vapour and ozone are largely independent of initial conditions for these tracers. That is, water vapour for TST is given by the minimum saturation mixing ratio. For ozone, the in- tegrated production along trajectories is of the same order of magnitude as the initialisation ozone mixing ratio. Conversely, the tracer predictions of the stratospheric ensemble strongly reflect initial conditions. That is, the minimum saturation mixing ratio encountered along trajectories that stay in the stratosphere is often $30 \%$ and higher (see below) than the initialisation value for water vapour, and hence the predicted value is the initialisation value. For ozone, production along the path of the stratospheric ensemble does play a role, but because of the generally much larger ozone concentrations in the stratosphere than in the troposphere, the initial concentration often dominates the predicted concentrations.

\subsection{Water vapour model}

We predict water vapour in the TTL (at the starting location of the backtrajectories, see Fig. 1) based on condensation and complete fall-out of the condensate along the trajectory. It is known that stratospheric water vapour predictions based on the minimum saturation mixing ratio from ERA-Interim data are drier than observed (James et al., 2008; Liu et al., 2010). Following the approach of James et al. (2008) condensation in our model occurs every time relative humidity exceeds $130 \%$. This threshold is well within the uncertainties of ice nucleation, and supersaturation with respect to ice is frequently observed (e.g., Krämer et al., 2009). But we emphasize that the point here is simply to achieve better agreement with measurements without any claim about cloud microphysical aspects. The trajectories are initialised with ERA-Interim water vapour mixing ratios. Model results for TST trajectories are independent of this initialisation, but for the stratospheric ensemble, relative humidity along the trajectory frequently stays below $130 \%$, such that the predicted water vapour for this ensemble essentially reflects initial conditions. Model results are interpreted only in terms of differences between the two trajectory methods.

\subsection{Ozone model}

For ozone, trajectories are initialised with ozone mixing ratios from ERA-Interim, and subsequent integration of the dominant production due to oxygen photolysis (see Avallone and Prather, 1996) and loss through $\mathrm{HO}_{\mathrm{x}}$ radicals (see e.g., Osterman et al., 1997). To overcome the difficulty of modelling the tropospheric ozone production due to hydrogen and nitrogen radicals (Wennberg et al., 1998), which requires very detailed information about the atmospheric composition, ozone values below $360 \mathrm{~K}$ potential temperature are prescribed from ERA-Interim. For the photolysis calculation with the CLaMS photolysis scheme (Meier et al., 1982; Becker et al., 2000), a climatological ozone field (Grooß and Russell, 2005), based on measurements from the Halogen Occultation Experiment (HALOE version 19 data, see Russell et al., 1993), is used as background. The $\mathrm{HO}_{\mathrm{x}}$ fields are taken from a model (CLaMS) based climatology. All 
calculations shown here include the loss from reaction with $\mathrm{HO}_{\mathrm{x}}$, but we show in Appendix A that neglecting the loss process would not change results significantly.

This simple ozone model captures the most important chemical processes controlling ozone in the tropical lower stratosphere and around tropopause levels, but not further below in the troposphere.

For the stratospheric trajectories that cannot be traced back to the troposphere and which are initialised with stratospheric ozone concentrations, the initial value is often larger than the integrated production. As such, results are sensitive to initial conditions. We evaluate the sensitivity to ozone initial conditions with a calculation where we use a zonal mean HALOE ozone climatology (further details in Sect. 2.4) instead of the ERA-Interim ozone field as initial condition. In the region of interest, ERA-Interim ozone concentrations are generally higher compared to the HALOE climatology and results based on the two initialisations yield a corresponding offset. Similarly to the case of water vapour, the emphasis of this paper is on differences in model predicted ozone between the two trajectory calculations, and these differences are robust to variations in initial conditions.

\subsection{Observations}

We compare the model predictions for water vapour and ozone against observations from different sensors and platforms. For the reconstructions of tropical mean fields and profiles, we compare the model predictions with observations from the Halogen Occultation Experiment (HALOE). HALOE measurements of water vapour and ozone are binned into zonal mean, monthly means averaged over the period 2001-2005, using the method of Grooß and Russell (2005). For comparison with 'tropical' mean profiles and timeseries, data are averages between $20^{\circ} \mathrm{S}-20^{\circ} \mathrm{N}$ in latitude. For the sensitivity calculation with respect to initial conditions, the HALOE initialisation data is binned on a regular grid in equivalent latitude (grid spacing of $15^{\circ}$ ), with equivalent latitude defined according to Nash et al. (1996).

For ozone, we also show measurements from the Southern Hemisphere Additional Ozone (SHADOZ) (Thompson et al., 2007) network, whereby we use a subset of seven stations as defined in Randel et al. (2007) to construct a "tropical mean" profile.

For the comparison with in-situ measurements, we use the Fast In-Situ Hygrometer FISH (Zöger et al., 1999) total water measurements and the ozone measuements from the Fast OZone ANalyser FOZAN (Ulanosvky et al., 2001) obtained during the SCOUT-O3 tropical campaign (as explained above). Further, we calculated a "typical" profile of water vapour and ozone from HALOE data for the period and region covered by the SCOUT-O3 tropical campaign. To this end, we average all HALOE measurements obtained between 15 November and 15 December 2005 within the region of $80^{\circ} \leq$ longitude $\leq 160^{\circ}$ and $-15^{\circ} \leq$ latitude $\leq 10^{\circ}$ ).

\section{Ozone and water vapour in the TTL}

\subsection{Reconstruction of tropical mean and local in-situ observations}

Figure 2 shows the annual cycle of water vapour and ozone at $400 \mathrm{~K}$, averaged between $\pm 20^{\circ}$ latitude. Model predicted mean water vapour mixing ratios are in agreement with observations as expected from the configuration of the model (Sect. 2.2). The slight phase shift between model calculations and observations is similar to that reported by Fueglistaler et al. (2005). Of relevance here, however, is the fact that the diabatic and kinematic model calculations give fairly similar results.

For ozone, the model predictions roughly span the range from low-biased (diabatic calculations using HALOE initialisation) to high-biased (kinematic calculations using ERAInterim initialisation). The differences between predicted ozone concentrations follow a simple pattern: calculations initialised with HALOE yield lower concentrations than those initialised with the ERA-Interim ozone field, and the kinematic calculations yield higher concentrations than those based on the diabatic trajectory calculations. Importantly, the differences between kinematic and diabatic calculations (about 20\% for either initialisation) are much larger for ozone than for water vapour.

The seasonality of the model predicted ozone fits observations reasonably well, with a tendency to overestimate the amplitude in particular for the diabatic trajectory calculations. Overall, however, agreement with observations is reasonable in particular if one bears in mind the observational uncertainty between HALOE and SHADOZ estimates, evident from the difference between HALOE and SHADOZ mean concentrations and their variance in Fig. $2 b$. The most interesting result is the difference between the calculations based on kinematic and diabatic trajectories, with the kinematic ozone predictions significantly higher than the diabatic predictions.

Figure $2 \mathrm{c}$ shows the predicted ozone mixing ratios based solely on the initial values, i.e. the passively advected ozone. The figure shows that the different initialisation accounts for much of the difference between the full model calculations.

Figure $2 \mathrm{~d}$ shows the predicted ozone based only on chemistry along the trajectories. We note that for all calculations, the integrated production over the 3-month trajectory period is about half (and less) that of the initialisation field. The differences between diabatic and kinematic ozone predictions due to chemistry and passive transport are of the same order of magnitude. Also, the seasonality of predicted ozone concentrations is not a result of chemical production along these 3-month trajectories, but of passive transport of the initialisation values. The chemical production along the 3-month back trajectories yields a semiannual cycle that arises from the annual cycle of the Earth's inclination. 

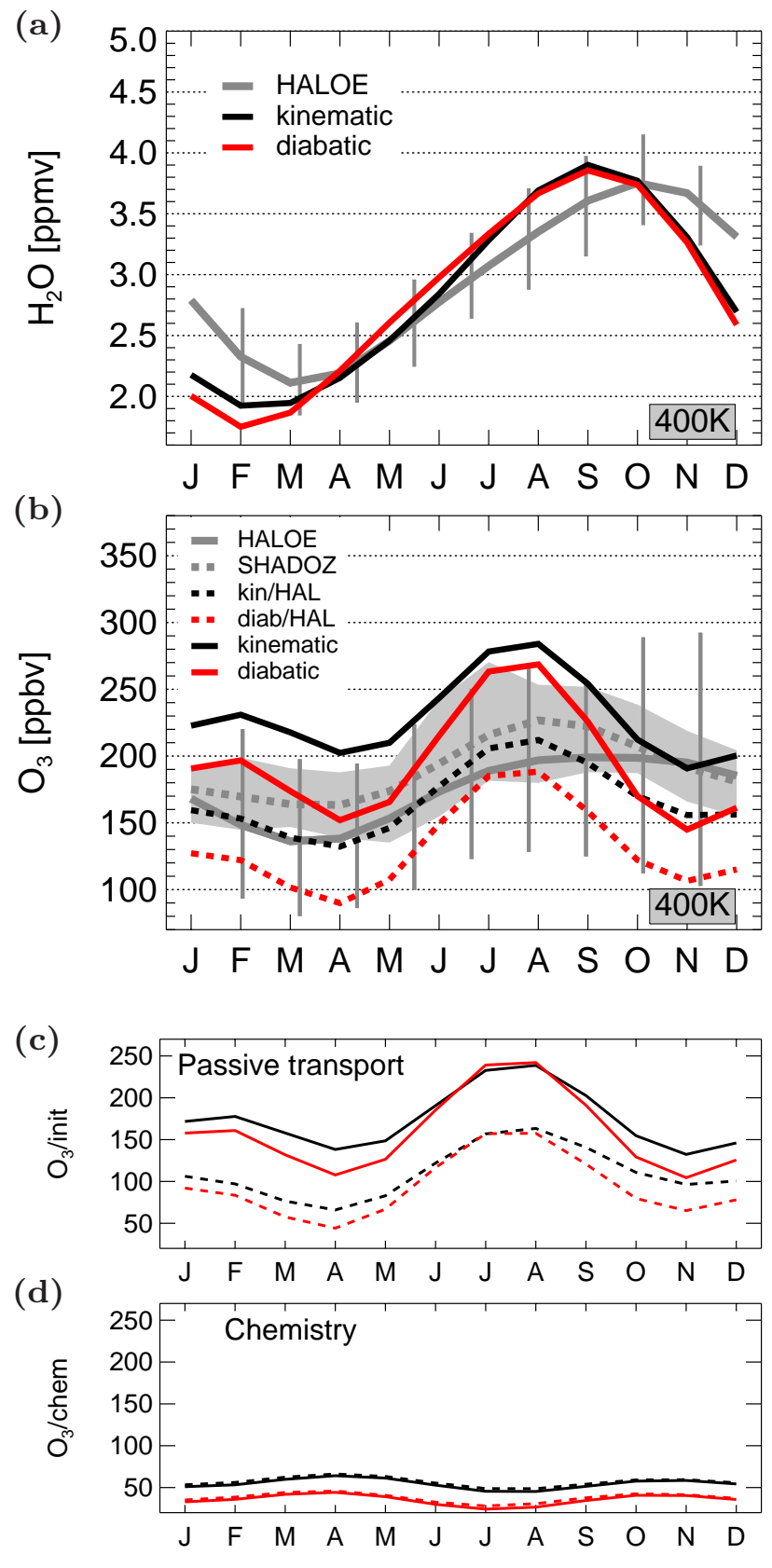

Fig. 2. Monthly mean, tropical mean $\left(20^{\circ} \mathrm{S}-20^{\circ} \mathrm{N}\right.$ latitude $)$ mixing ratios at $400 \mathrm{~K}$ for (a) water vapour and (b) ozone from HALOE (averaged for years 2001-2005; grey solid lines, with range of \pm 1 standard deviation as vertical bars), and from SHADOZ (19982006; for ozone only, grey dotted line and grey shading for range of \pm 1 -standard deviation). The model predictions based on initialisation with ERA-Interim are shown as solid lines, and with initialisation based on HALOE as dashed lines (for ozone only); calculations based on kinematic trajectories in black, diabatic trajectories in red. (c) Predicted ozone concentrations based on initial conditions only (i.e. passively advected ozone); same conventions as in (b). (d) Predicted ozone concentrations based on chemistry along trajectories; same conventions as in (b). All lines are harmonic fits to the monthly mean values, using annual and semi-annual harmonics.
An integration length of 90 days for trajectories started on $400 \mathrm{~K}$ potential temperature in the tropics is close to the expected mean transport time from the upper troposphere to this level. Hence, one may suspect that the lack of an annual cycle in the TST-ensemble in Fig. 2d arises from truncation of the age-spectrum (compare Hall and Plumb, 1994; Waugh and Hall, 2002) at a value close to the mean transport timescale. However, sensitivity calculations using 5 month instead of 3 month back trajectories give very similar results (not shown). This result supports the argument of Konopka et al. (2009) and Konopka et al. (2010) that the annual cycle in lower stratospheric ozone is a consequence of more inmixing of stratospherically old air during the boreal summer months.

This detailed analysis shows that for the model predictions of the annual cycle of ozone at $400 \mathrm{~K}$, the total difference (difference in initialisation with identical fields, and chemical production) between the volume mixing ratios of the kinematic and diabatic calculation is about $50 \mathrm{ppbv}$ (parts per billion by volume), which is similar to the difference arising from using different initialisation fields.

We next analyse profiles of model predicted ozone and water vapour for the observations during the tropical SCOUTO3 campaign. Figure 3 a shows the FISH total water profile, HALOE water vapour profile, and the model water vapour predictions. Figure $3 \mathrm{~b}$ shows the same information for ozone. Note that the flight track portions used for these profiles are not identical for the two species, as instruments were not always operational at the same time.

For water vapour, the in-situ measurements are drier than HALOE at tropopause levels ( $375 \mathrm{~K}-395 \mathrm{~K}$ potential temperature). The model predictions are generally within the range of in-situ observations (though a dry tendency is noted for levels below $400 \mathrm{~K}$ ), and the difference between kinematic and diabatic model calculations around $400 \mathrm{~K}$ is larger than in the calculations of the annual cycle (Fig. 2a).

For ozone, the in-situ measurements and HALOE measurements agree quite well. For the ozone model predictions, we find again the same pattern with respect to initialisation and trajectory type as seen in the annual cycle (Fig. 2b). An interesting difference between the SCOUT-O3 ozone profile prediction (Fig. 3b) and the prediction for the annual cycle at $400 \mathrm{~K}$ (Fig. 2b) is that the differences between diabatic and kinematic calculations (i.e. red versus black lines of either initialisation) are much larger than the differences between the two initialisations (i.e. solid versus dotted of either trajectory type).

Figure $3 \mathrm{c}$ shows the same analysis for tropical mean ozone concentrations. As before, the diabatic trajectories yield lower ozone mixing ratios than the kinematic trajectories, and the calculations initialised with HALOE ozone yield lower values than those with ERA-Interim ozone. Further, the figure shows that the model predictions of the TST-ensemble are very similar between kinematic and diabatic trajectories, which confirms that the differences in the 

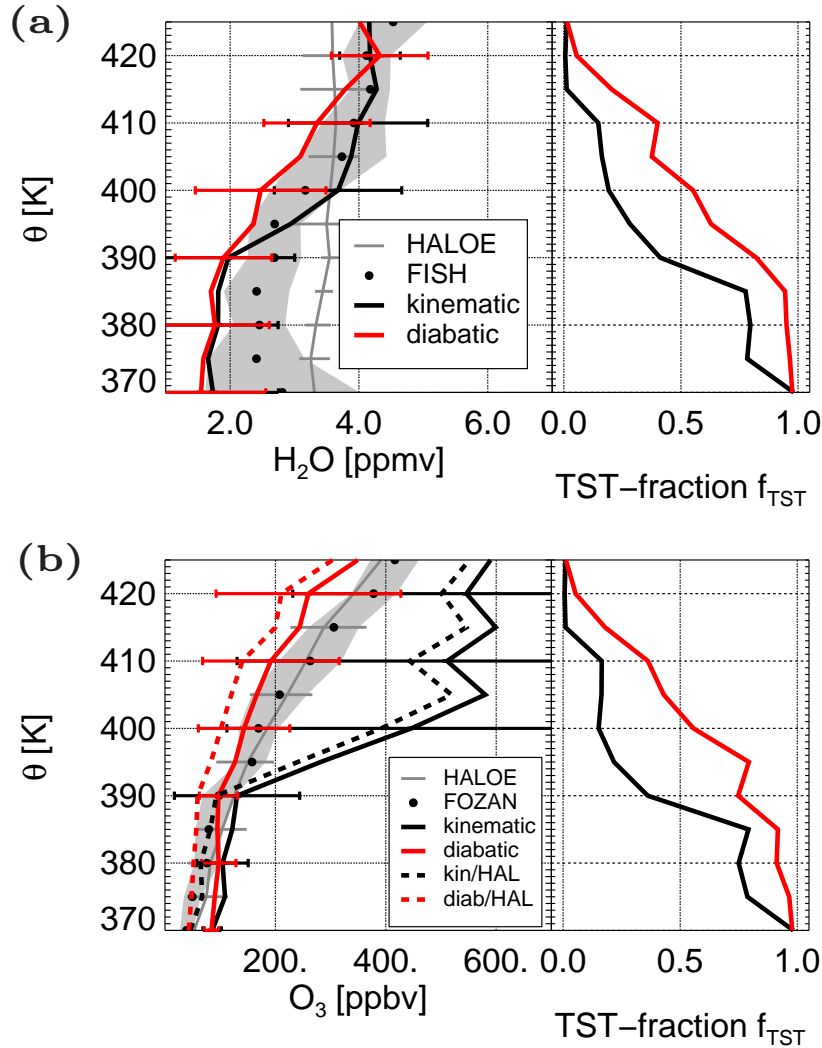

(c)

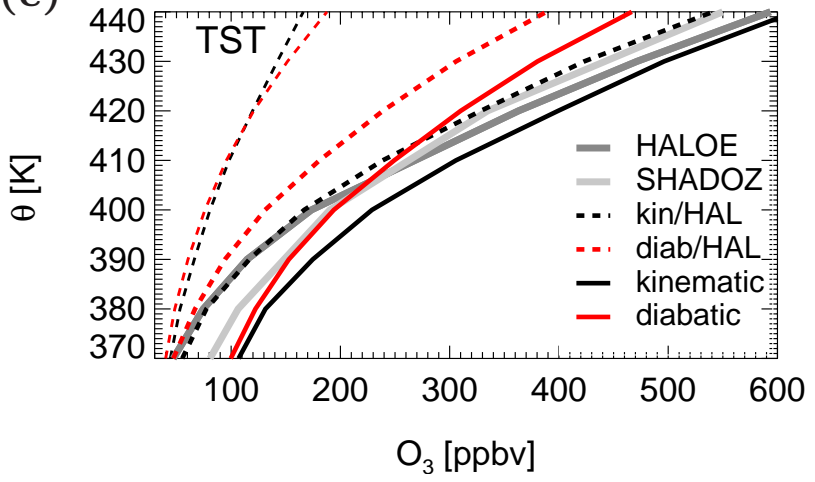

Fig. 3. Mean water vapour (a) and ozone (b) profiles during the SCOUT-O3 campaign, in $5 \mathrm{~K}$ potential temperature bins. In-situ observations are from the FISH (water vapour, black dots; grey range 1-standard deviation) and FOZAN (ozone, black dots, grey range 1-standard deviation) instruments. Grey solid lines (bars show 1-standard deviation) are HALOE water vapour and ozone measurements during the SCOUT-O3 campaign (see text). Model predictions based on kinematic (black) and diabatic (red) trajectories with initialisation based on ERA-Interim are shown as solid, with ozone initialisation based on HALOE as dashed curves. Panels on righthandside show TST fractions (criterion $350 \mathrm{~K}$ potential temperature, see text). (c) Profiles of tropical mean ozone concentrations from HALOE, SHADOZ and the 4 model calculations as labelled. Thin dashed red/black lines are ozone predictions from the TST ensemble with initialisation from HALOE ozone. predicted ozone field are driven by the stratospheric trajectory ensemble.

\subsection{Importance of stratospheric trajectories}

We use the separation of trajectories into TST trajectories and purely stratospheric (those that cannot be traced back to below $350 \mathrm{~K}$ ) trajectories to discuss the differences between diabatic and kinematic model predictions in more detail. The right part of the panels of Fig. 3a/b show the TST fractions for the calculations. The diabatic trajectories have generally a higher TST-fraction than the kinematic trajectories due to the higher vertical dispersion of the latter (further discussed below). Up to about $390 \mathrm{~K}$ potential temperature, model predictions are dominated by TST trajectories (with low initial ozone, irrespective of the initialisation field), while above the results are increasingly dominated by the stratospheric ensemble.

Figure 4 shows the probability distribution functions (PDFs) of the differences between measurements and model predictions for the in-situ profiles of water vapour and ozone between 390 and $420 \mathrm{~K}$. The figure shows that for water vapour, the distributions are slightly skewed (for diabatic/kinematic to negative/positive differences), and that the shapes of the PDF are broadly similar for kinematic and diabatic trajectories, as well as for the TST-ensemble of the kinematic trajectories (grey shading). For ozone, the figure shows that the kinematic trajectory calculation has a distinct tail of very high biases. Comparison with the PDF of the TST-ensemble shows that this tail of high biases is entirely due to stratospheric trajectories. In the case of the diabatic trajectories, no tail of very high biases is observed (note the logarithmic scale).

To summarise, our analysis shows that model predictions of ozone are sensitive to initialisation and transport, and that it is in particular the stratospheric trajectory ensemble that is most sensitive to these factors. While the sensitivity to the initialisation field is not surprising, the much higher sensitivity to transport of ozone than water vapour suggests that ozone is a much better tracer to study important aspects of transport that observations of water vapour cannot resolve.

\section{Diabatic versus kinematic transport}

The bulk transport characteristics for TST trajectories calculated from ERA-Interim data, like TTL residence times, are similar for kinematic and diabatic trajectories (Ploeger et al., 2010; Liu et al., 2010). Figure 5 shows the position of the global (top panels) and in-situ trajectories (bottom panels) when tracing them back in time for 60 days. The main differences observed here, already noticed by Ploeger et al. (2010) and Liu et al. (2010), are the higher vertical dispersion and the occurrence of descent in the equatorial lower stratosphere for the kinematic trajectories. Consequently, the positions 

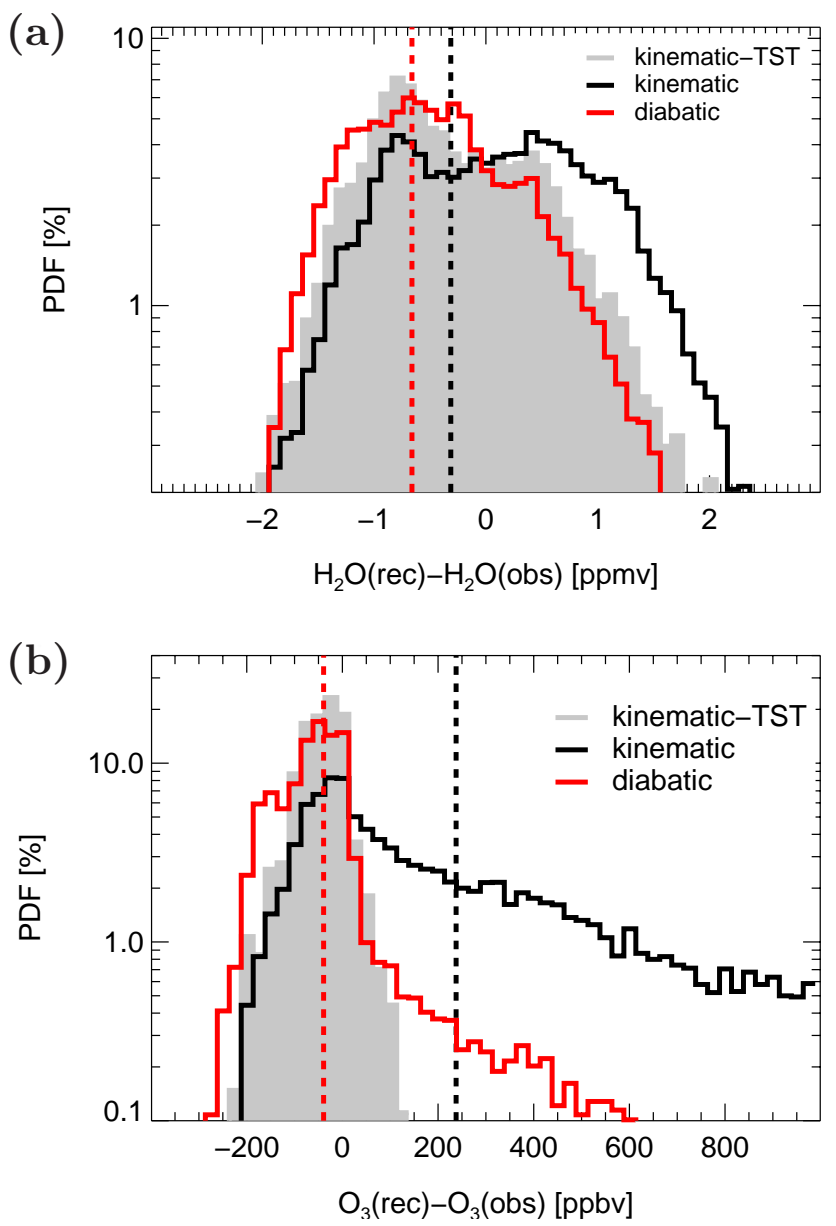

Fig. 4. Probability distribution functions (PDFs) of differences between observed and reconstructed water vapour (a) and ozone (b) between 390 and $420 \mathrm{~K}$. The bin size is $25 \mathrm{ppbv}(0.1 \mathrm{ppmv})$ for ozone (water vapour). Dashed lines show the means of the distributions. The grey shading shows the PDF for the kinematic TST ensemble.

where the kinematic model calculations are initialised are more widespread than those of the diabatic calculations. The figure shows that the differences are particularly prominent for the case study of the SCOUT-O3 tropical campaign.

The differences in dispersion between ERA-Interim kinematic and diabatic trajectory calculations arise both from larger noise in the instantaneous vertical wind field than diabatic heating rates, and from large-scale and time-mean systematic differences in vertical transport. Horizontal maps of large-scale differences between diabatic and kinematic mean cross-isentropic trajectory motion in the upper TTL between 380-400 K for boreal winter 2002 were shown in (Ploeger et al., 2010, Fig. 6). The velocity maps for the SCOUTO3 period (November/December 2005) are very similar (not shown). In particular, the maritime continent and Northern Australia turn out as regions where cross-isentropic motion is directed upward for diabatic trajectories and downward for kinematic trajectories. This net subsidence in the inner tropics vertical $\omega$ wind field shows up very prominently also in Fig. 5b.

In the following, we demonstrate that ozone is a remarkable tracer for dispersion, and that much of the differences between kinematic and diabatic model predictions are a direct consequence of the sensitivity of ozone to trajectory dispersion, caused by inhomogeneities in the wind field. In addition to model predictions of ozone, we calculate the vertical "dispersion" of trajectories in terms of their variance in potential temperature after 3 months of an ensemble of back trajectories started in a given longitude/latitude grid box. For each bin the mean potential temperature variance (see Sparling et al., 1997) is defined as

$\left\langle\delta \theta^{2}\right\rangle=\left\langle(\theta-\langle\theta\rangle)^{2}\right\rangle$,

and hence measures the vertical spread of the trajectory ensemble. Note that the integration over 3 months is longer than is commonly done, in order to obtain a measure that can be directly compared to the ozone predictions (which are also initialised after 3 months).

Figure 6 shows the dispersion (a) and ozone (b) results for a typical calculation where trajectories are started on $400 \mathrm{~K}$ on 20 November 2005. The figure shows the anomalies (after subtraction of the mean value over the tropics) of the differences between kinematic and diabatic trajectory calculations. This calculation eliminates mean biases in ozone and dispersion, and leaves only the spatial pattern in differences between the two calculations. The correspondence between the dispersion and ozone anomalies is very good, with larger vertical dispersion being positively correlated with larger ozone concentrations. The region over Northern Australia where the SCOUT-O3 campaign took place stands out as a region of maximum differences in both vertical dispersion and predicted ozone between kinematic and diabatic transport. The large difference in dispersion results partly from the largescale velocity patterns, showing mean ascent for diabatic and mean subsidence for kinematic trajectories (compare Ploeger et al., 2010, Fig. 6) and partly from the higher small-scale noise in kinematic velocities (not shown). In the following, we show that the correlation is robust, but that the geographical location of maxima vary with time, such that model comparisons with in-situ data as shown in Fig. 3b may give different results for different campaigns.

Figure 7 shows similar information for trajectory calculations started once per month in 2002, expressed as a correlation plot. The $\mathrm{x}$-axis is the kinematic-diabatic difference in potential temperature variance (dispersion), while the $y$ axis is the corresponding difference for water vapour (a) and ozone (b). Each symbol represents one horizontal bin (as defined in Fig. 6) for one month. The figure shows that for water vapour no correlation is observed (correlation coefficient $r=-0.03$ ), whereas for ozone the correlation between ozone and dispersion differences is high, with correlation coefficient $r=0.84$. The red symbols are the twelve monthly data 
(a)

(c)
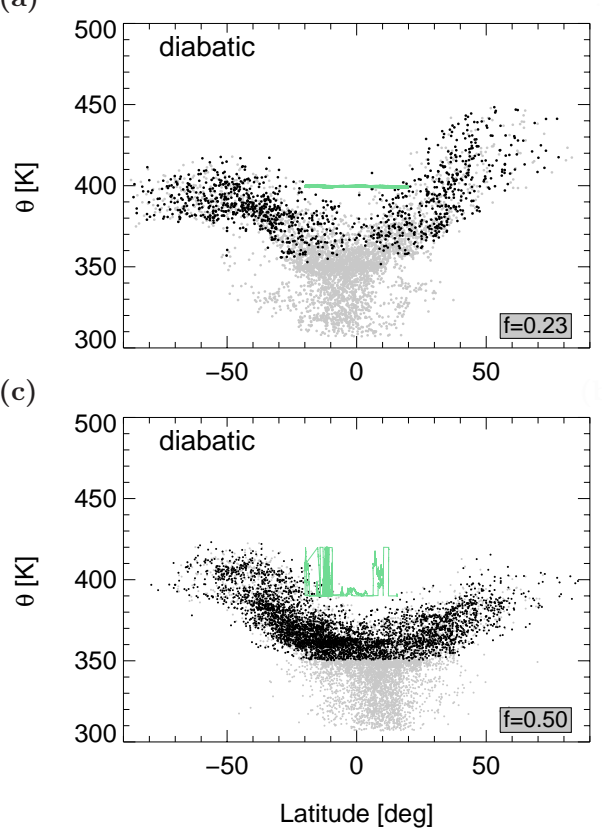

(b)

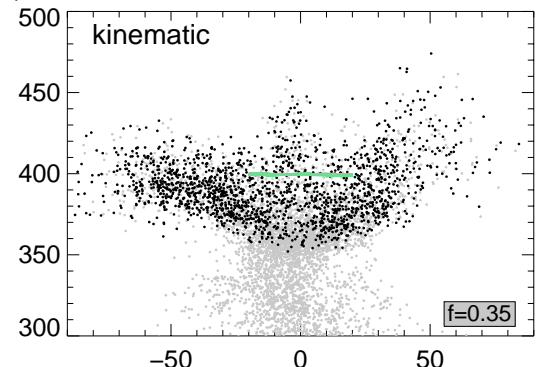

(d)

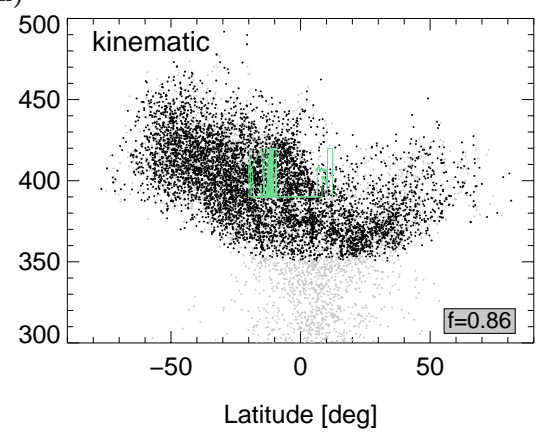

Fig. 5. (a/b) Locations of backtrajectories in the latitude/potential temperature plane 60 days prior to the start time (left: diabatic; right: kinematic), started on $400 \mathrm{~K}$ potential temperature surface between $\pm 20^{\circ}$. End points of stratospheric trajectories are in black, of TST trajectories (see text) in grey and the starting locations $(400 \mathrm{~K})$ in green. The number $f$ denotes the fraction of stratospheric (non-TST) trajectories. (c/d) Same as (a/b), but for SCOUT-O3 trajectories.

points for the area over Northern Australia. This region has always a high difference in ozone and dispersion, but is not always the location of the maximum difference. Similarly, the region of the maritime continent (green data points) is also a region of a generally high difference although it is not the case for the calculation for 20 November 2005 (Fig. 6).

\section{Discussion}

\subsection{The difference between water vapour and ozone as transport tracers}

The higher sensitivity of ozone than water vapour to differences in transport as between ERA-Interim kinematic and diabatic trajectories is primarily caused by the much larger vertical and horizontal gradients of stratospheric ozone than water vapour. With current tropospheric methane concentrations the maximum vertical increase in stratospheric water vapour is about a doubling of water vapour entry mixing ratios. Conversely, net ozone production maximises in the tropical lower stratosphere, increasing ozone entry volume mixing ratios from about $100 \mathrm{ppbv}$ by a factor 100 to about $10 \mathrm{ppmv}$ (parts per million by volume) around $10 \mathrm{hPa}$. Consequently, even small differences in the initialisation positions and pathways of the stratospheric trajectory ensemble have a large impact on predicted ozone, while they have only a small impact on water vapour.
For the TST-ensemble, we find that both ozone and water vapour are relatively insensitive to the choice of the transport representation. For water vapour, the insensitivity arises from the "loss of memory of initial conditions" as a trajectory approaches the minimum saturation mixing ratios at the tropical tropopause. The difference in the distribution of the position of minimum saturation mixing ratios between kinematic and diabatic ERA-Interim trajectories induces only minor differences in model predicted entry mixing ratios (see also Liu et al., 2010). In agreement with previous work (Krüger et al., 2008) we find that the patterns of distribution of minimum saturation mixing ratio of TST-trajectories (Bonazzola and Haynes, 2004; Fueglistaler et al., 2005; Kremser et al., 2009) are a robust feature of TST.

The model predictions of ozone for TST trajectories only are insensitive to transport pathways, because for ERAInterim kinematic and diabatic trajectories the typical pathways and times to rise into the stratosphere are very similar (compare Ploeger et al., 2010). Also the sensitivity to initial conditions is much smaller for ozone predictions from TST than to predictions from stratospheric trajectories, because for TST the relative importance of integrated production compared to passive transport is higher than for stratospheric trajectories. 
(a)

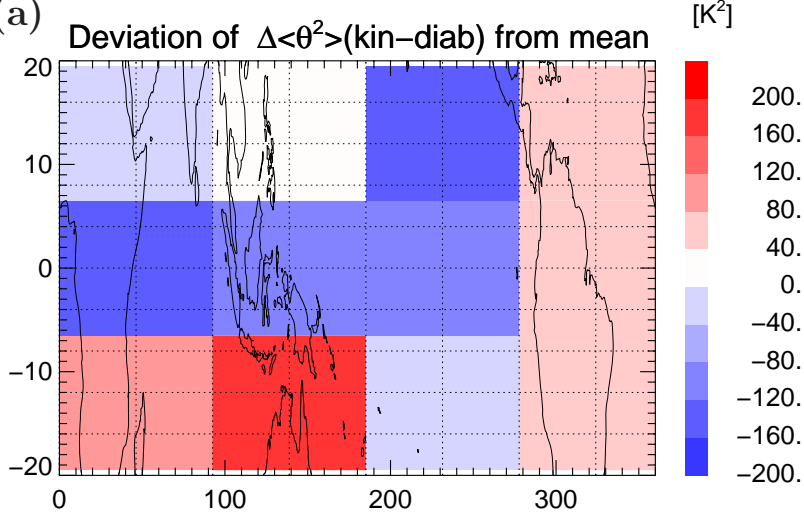

(b)

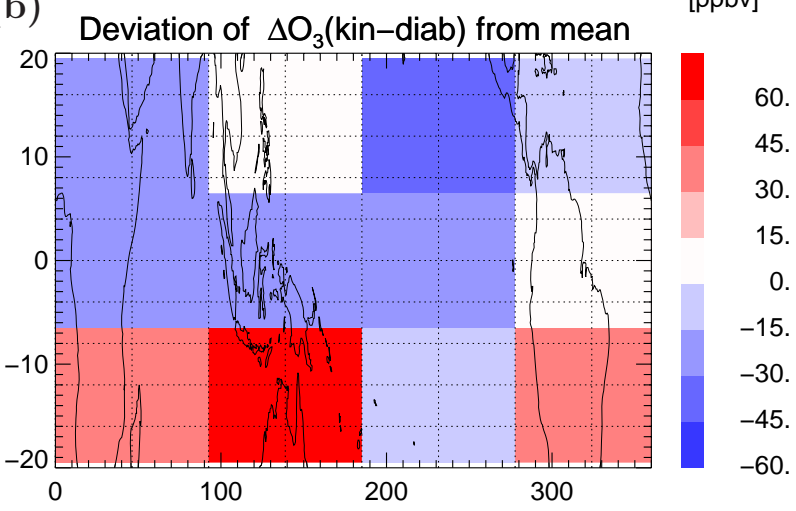

Fig. 6. Anomaly (from tropical mean) of kinematic-diabatic dispersion $\left\langle\delta \theta^{2}\right\rangle$ difference (a) and ozone difference (b) at $400 \mathrm{~K}$ on 20 November 2005. Data is binned into $13^{\circ} \times 90^{\circ}$ latitude-longitude bins. Red/blue indicates positive/negative anomaly. Note that the pattern varies with time (see also Fig. 7).

\subsection{Mean transport and dispersion in the TTL and lower stratosphere}

Variations in tropical stratospheric upwelling are a direct consequence of variations in the strength of the wave-driven stratospheric circulation (Holton et al., 1995). Analysis of the "atmospheric tape recorder signal" of tropical stratospheric water vapour (Mote et al., 1996) for estimates of upwelling, and model validation is a standard practice (Mote et al., 1998). Avallone and Prather (1996) showed that in principle the same information can be obtained from the vertical gradient in tropical lower stratospheric ozone. Randel et al. (2007) and Konopka et al. (2009) further studied the relation between upwelling and ozone, and the possible role of horizontal, isentropic in-mixing.

Our results using the full 4-dimensional transport as represented by trajectories suggest that diabatic dispersion may play a significant role for tropical lower stratospheric ozone concentrations. Consequently, analyses based on a model of the timescale of mean transport may be misleading as the "tail" of the stratospheric age-of-air distribution may have a
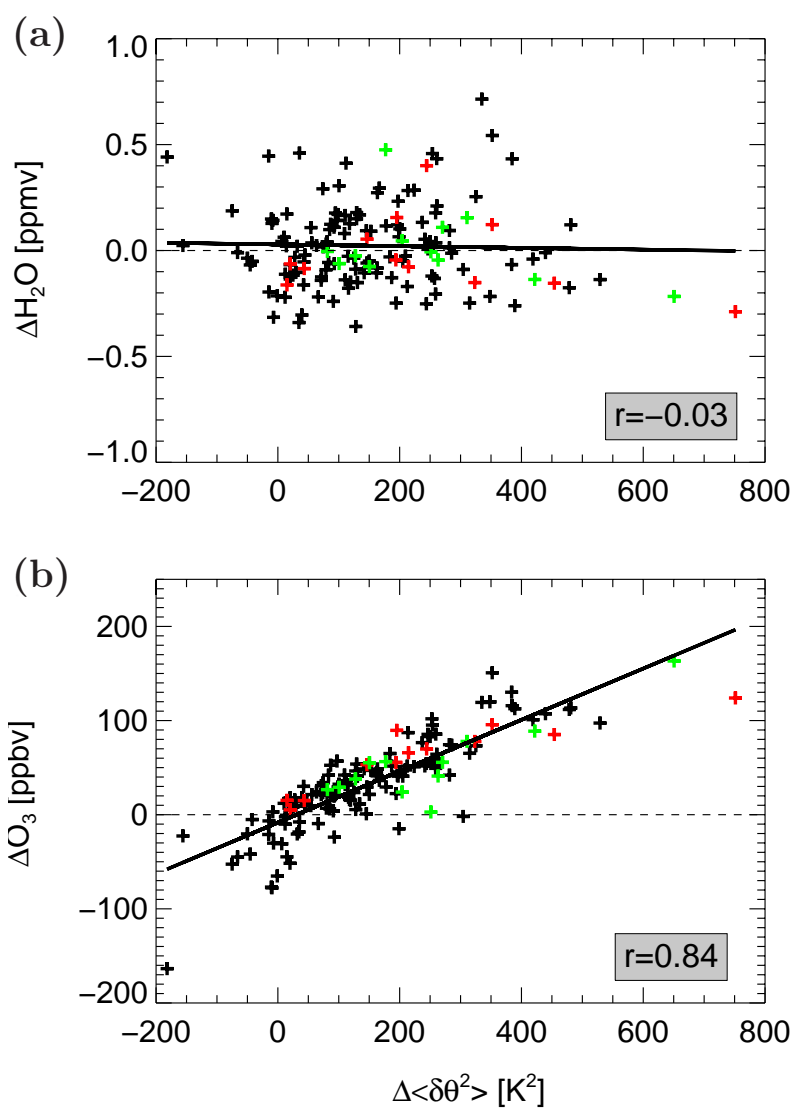

Fig. 7. (a) Correlation between difference in model predicted water vapour and difference in dispersion (quantified from potential temperature variance $\left\langle\delta \theta^{2}\right\rangle$, see text), with difference denoting the difference between kinematic and diabatic backtrajectory calculations, started in the tropics on $400 \mathrm{~K}$ potential temperature once per month over the year 2002. Each symbol represents the water vapour and dispersion difference for one grid box of $13^{\circ} \times 90^{\circ}$ latitude/longitude (compare Fig. 6). (b) As (a) but for ozone. Red/green data points in both panels refer to the grid box over Northern Australia and the maritime continent region (see Fig. 6). The correlation coefficient $r$ is shown in each panel.

large influence on tropical lower stratospheric ozone mixing ratios.

Figure 8 shows the tropical mean observed profiles and the kinematic and diabatic model predictions using the ERAInterim ozone field as shown in Fig. 3c. The figure further shows the profile of predicted ozone for the diabatic trajectory calculations where the model diabatic heating rates were multiplied with a factor 0.7 . This procedure reduces to some extent dispersion, but its main effect is a reduction in mean upwelling by about $30 \%$ (see Liu et al., 2010). The figure shows that the diabatic calculation with $30 \%$ reduced upwelling gives an ozone profile that is virtually identical to that of the kinematic calculation despite its much lower vertical dispersion. 


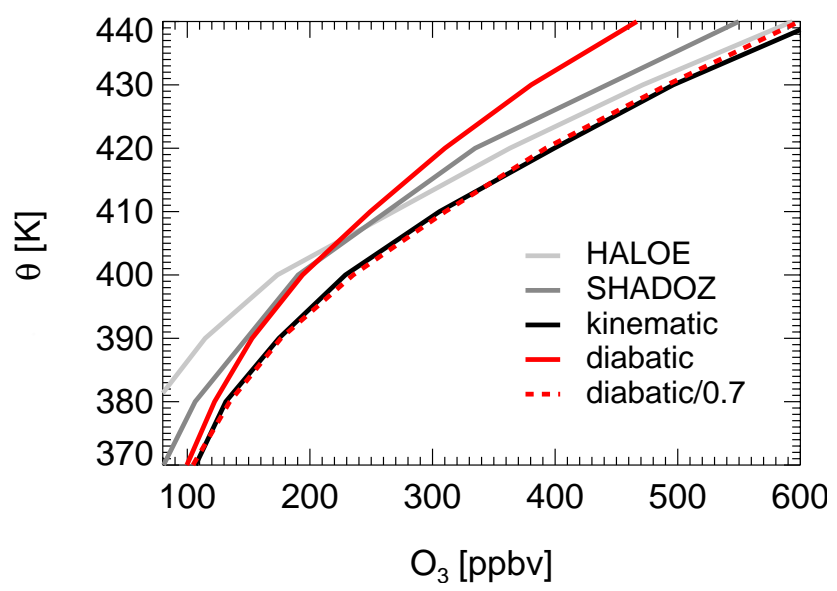

Fig. 8. Mean tropical ozone profiles, reconstructed from trajectories (diabatic; diabatic with vertical velocity multiplied by a factor 0.7; kinematic), HALOE and SHADOZ observations.

Since neither true dispersion nor upwelling velocity in the TTL are known exactly, it is not possible to precisely deduce any one of the two parameters from ozone alone. Rather, it may be that the combination of phase propagation of the water vapour tape recorder signal with the annual cycle in ozone concentrations allows one to determine both mean upwelling and dispersion accurately. Such an analysis, however, is beyond the scope of the calculations used here based on relatively short trajectory integration periods (in order to capture the water vapour phase propagation, trajectories would have to be started throughout the lower stratosphere and integrated for much longer periods).

\subsection{Constraints for the lower stratospheric circulation}

Our analysis suggests that a combination of ozone and water vapour may be able to constrain transport in the TTL and lower stratosphere better than water vapour alone. In particular, the possibility that very deep convection overshooting its level of neutral buoyancy induces a diabatic downwelling over regions of intense convection (Sherwood, 2000) remains a subject of interest that has not yet been conclusively resolved.

The calculations presented in this paper yield ambiguous results with respect to this question. As emphasised throughout this paper, due care should be taken when interpreting absolute values of predicted ozone and water vapour concentrations. However, the following aspects are noteworthy in this context.

The ERA-Interim vertical $\omega$ wind shows net downwelling in particular regions of the equatorial stratosphere, as depicted in (Ploeger et al., 2010, Fig. 6) (but note that averaged over the full tropics, the net motion is upward). It should be kept in mind here, that these regions of negative vertical velocities for kinematic trajectories (compare Ploeger et al.,
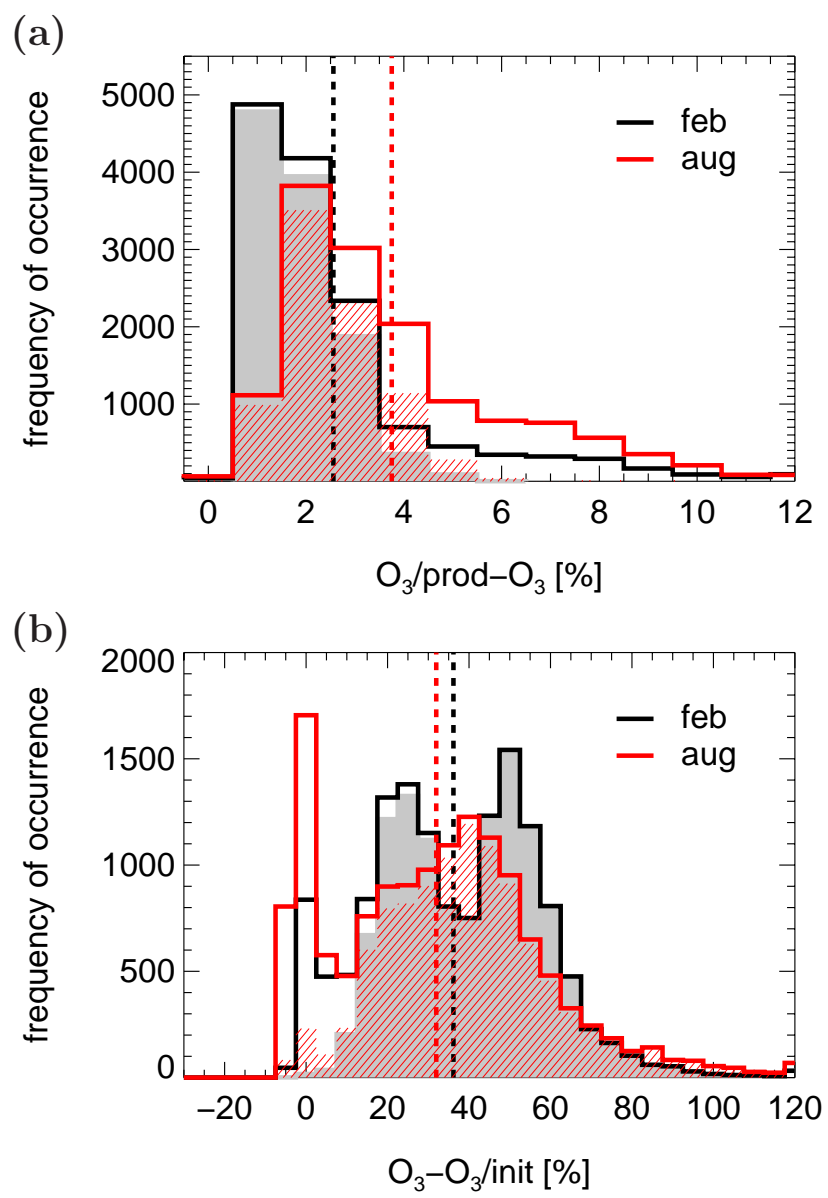

Fig. 9. (a) Effect of chemical ozone loss, calculated from the difference between trajectory reconstructed ozone from photolytical production only $\left(\mathrm{O}_{3}\right.$ /prod) and from both photolytical production and $\mathrm{HO}_{\mathrm{x}}$-loss, for February (black) and August (red), started at $400 \mathrm{~K}$ (see text). Frequency of occurrence for TST trajectories only is shown as grey shaded/red dashed area for February/August. (b) Net effect of chemistry, calculated as difference between trajectory reconstructed and passively transported (initialisation, $\mathrm{O}_{3}$ /init) ozone. The bin size is $1 \%$ and $5 \%$ in (a) and (b), respectively. Black/red dashed lines show the means of the distributions.

2010, Fig. 6) show cross-isentropic net downward motion and not the mean vertical $\omega$-wind, as explained in Sect. 4. It is presently not clear why there is some downwelling and it is, evidently, not clear whether this downwelling is real or an artefact of the ERA-Interim assimilation procedure. In any case, comparison between the kinematic and diabatic trajectory calculations, with the vertical $\omega$-wind field showing downwelling and the diabatic heating in the same reanalysis showing broad upwelling throughout the tropics, may allow some insight about the implications of downwelling on ozone.

The model calculations based on diabatic trajectories and initialised with HALOE have a general tendency to give a profile that is low biased when compared to the HALOE 
tropical profile as well as the HALOE or FOZAN profiles for the SCOUT-O3 campaign (Figs. 2b, 3b, c). Conversely, the calculations initialised with HALOE and using kinematic trajectories for transport yield good agreement for the tropical mean ozone profile (Figs. 2b, 3c). However, for the SCOUT-O3 campaign, where the largest impact from downwelling would be expected because of the proximity to the maritime continent region, the kinematic trajectories that include downwelling (Fig. 5b) yield a large high bias (Fig. 3b), arguing against the occurrence of equatorial lower stratospheric downwelling.

Hence, the calculations presented here remain inconclusive with respect to the particular problem whether there is net upward or downward motion above the maritime continent. We anticipate progress if it were possible to constrain the timescale of troposphere-to-stratosphere transport to better than the $\pm 30 \%$ required to bring ozone predictions of diabatic and kinematic trajectories into agreement (note that from the water vapour tape recorder, ascent from tropopause to about $10 \mathrm{hPa}$ can be estimated fairly precisely, but not for the region around the tropopause, see also Liu et al., 2010).

\section{Conclusions}

In this paper, we have combined 3-month backtrajectories with a simple chemical model of ozone production, and of dehydration. results for ozone are sensitive to initial conditions. Due to some uncertainty in lower stratospheric ozone concentrations (measurements from different sensors and platforms differ on the order of $10-20 \%$ ), we have refrained from interpreting absolute values of model predictions. Rather, we have emphasised differences between model calculations using kinematic and diabatic trajectories. The results show that ozone is very sensitive to dispersion, much more so than water vapour. A robust result is that the larger the dispersion, the higher the model predicted ozone concentration. Ozone concentrations are also sensitive to the rate of diabatic ascent, and consequently there exists some ambiguity between rate of ascent and small-scale mixing. It is expected that this ambiguity also affects the conclusions that can be drawn from a comparison of observed ozone and that of Chemistry Climate Models. We expect that comparison between observed and modelled ozone could provide new constraints on transport in the TTL and lower stratosphere if it were possible to determine the timescale of ascent across the TTL more accurately than currently published estimates.

\section{Appendix A}

\section{Effect of production, loss and transport on ozone}

We illustrate the effect of production, loss and transport on backtrajectory predicted ozone in the upper TTL and lower tropical stratosphere. In Fig. 9a the effect of chemical loss $\Delta \mathrm{O}_{3}$ (loss) is shown for diabatic February/August (black/red) trajectories. Conclusions based on kinematic trajectories are identical. The effect of chemical loss is calculated from the difference between reconstructed ozone without chemical loss included, and reconstructed ozone (initialisation + production + loss). Figure 9a shows the frequency of occurrence distribution of chemical loss for the February/August trajectory ensembles (black/red). The distributions for TST trajectories only are shown as grey (February) and red (August) shadings. There is a short tail of the distributions at larger positive values, which is not present in the TST distributions. Thus, chemical loss has a larger effect on in-mixed (stratospheric trajectories) compared to tropical (TST trajectories) air. However, the peaks are narrow and centred near zero, showing that the additional effect of ozone loss reactions, is negligible.

The net effect of chemistry $\Delta \mathrm{O}_{3}(\mathrm{chem})$, calculated as frequency of occurrence of the difference between reconstructed ozone and passively transported ozone (initialisation mixing ratios) for the same trajectory ensembles as above, is shown in Fig. 9b. Obviously, for tropical air (TST) production (net chemistry $\approx$ production, as seen above) strongly modifies the initialisation values, in many cases by more that $50 \%$. For in-mixed air (stratospheric trajectories; difference between lines for all and for TST) production accounts for only a few percent of the final mixing ratios, which therefore almost equal the large stratospheric initialisation values.

Acknowledgements. We thank T. Birner for helpful discussions, $\mathrm{N}$. Thomas for programming support, M. Park for providing a SHADOZ-based ozone climatology and the ECMWF for reanalysis data support. F. Ploeger further thanks COST/WaVaCS (European Cooperation for Science and Technology/Atmospheric Water Vapour in the Climate System action) for funding a short term scientific mission at DAMTP/Cambridge, where main ideas for this work were developed.

Edited by: W. Lahoz

\section{References}

Avallone, L. M. and Prather, M. J.: Photochemical evolution of ozone in the lower tropical stratosphere, J. Geophys. Res., 101, 1457-1461, 1996.

Becker, G., Grooß, J.-U., McKenna, D. S., and Müller, R.: Stratospheric photolysis frequencies: Impact of an improved numerical solution of the radiative transfer equation, J. Atmos. Chem., 37, 217-229, doi:10.1023/A:1006468926530, 2000. 
Bonazzola, M. and Haynes, P. H.: A trajectory-based study of the tropical tropopause region, J. Geophys. Res., 109, 20112, doi: 10.1029/2003JD004356, 2004.

Brewer, A. W.: Evidence for a world circulation provided by the measurements of helium and water vapour distribution in the stratosphere, Q. J. Roy. Meteorol. Soc., 75, 351-363, 1949.

Brunner, D., Siegmund, P., May, P. T., Chappel, L., Schiller, C., Müller, R., Peter, T., Fueglistaler, S., MacKenzie, A. R., Fix, A., Schlager, H., Allen, G., Fjaeraa, A. M., Streibel, M., and Harris, N. R. P.: The SCOUT-O3 Darwin Aircraft Campaign: rationale and meteorology, Atmos. Chem. Phys., 9, 93-117, doi:10.5194/acp-9-93-2009, 2009.

Fueglistaler, S. and Haynes, P. H.: Control of interannual and longer-term variability of stratospheric water vapor, J. Geophys. Res., 110, 24108, doi:10.1029/2005JD006019, 2005.

Fueglistaler, S., Wernli, H., and Peter, T.: Tropical troposphereto-stratosphere transport inferred from trajectory calculations, J. Geophys. Res., 109, D03108, doi:10.1029/2003JD004069, 2004.

Fueglistaler, S., Bonazzola, S., Haynes, P. H., and Peter, T.: Stratospheric water vapor predicted from the Lagrangian temperature history of air entering the stratosphere in the tropics, J. Geophys. Res., 110, 8107, doi:10.1029/2004JD005516, 2005.

Fueglistaler, S., Dessler, A. E., Dunkerton, T. J., Folkins, I., Fu, Q., and Mote, P. W.: Tropical Tropopause Layer, Rev. Geophys., 47, RG1004, doi:10.1029/2008RG000267., 2009a.

Fueglistaler, S., Legras, B., Beljaars, A., Morcrette, J. J., Simmons, A., Tompkins, A. M., and Uppala, S.: The diabatic heat budget of the upper troposphere and lower/mid stratosphere in ECMWF reanalysis, Q. J. Roy. Meteorol. Soc., 135, 21-37, doi:10.1002/ qj.361, 2009b.

Gettelman, A. and Forster, P. M.: Definition and climatology of the tropical tropopause layer, J. Meteorol. Soc. Jpn., 80, 911-924, 2002.

Grooß, J.-U. and Russell, J. M.: Technical note: A stratospheric climatology for $\mathrm{O}_{3}, \mathrm{H}_{2} \mathrm{O}, \mathrm{CH}_{4}, \mathrm{NO}_{x}, \mathrm{HCl}$ and $\mathrm{HF}$ derived from HALOE measurements, Atmos. Chem. Phys., 5, 2797-2807, doi:10.5194/acp-5-2797-2005, 2005.

Hall, T. M. and Plumb, R. A.: Age as a diagnostic of stratospheric transport, J. Geophys. Res., 99, 1059-1070, 1994.

Highwood, E. J. and Hoskins, B. J.: The tropical tropopause, Q. J. Roy. Meteorol. Soc., 124, 1579-1604, 1998.

Holton, J. R. and Gettelman, A.: Horizontal transport and the dehydration of the stratosphere, Geophys. Res. Lett., 28, 2799-2802, 2001.

Holton, J. R., Haynes, P., McIntyre, M. E., Douglass, A. R., Rood, R. B., and Pfister, L.: Stratosphere-troposphere exchange, Rev. Geophys., 33, 403-439, 1995.

Hoor, P., Wernli, H., Hegglin, M. I., and Boenisch, H.: Transport timescales and tracer properties in the extratropical UTLS, Atmos. Chem. Phys., 10, 7929-7944, doi:10.5194/ acp-10-7929-2010, 2010.

James, R. and Legras, B.: Mixing processes and exchanges in the tropical and the subtropical UT/LS, Atmos. Chem. Phys., 9, 2538, doi:10.5194/acp-9-25-2009, 2009.

James, R., Bonazzola, M., Legras, B., Surbled, K., and Fueglistaler, S.: Water vapor transport and dehydration above convective outflow during Asian monsoon, Geophys. Res. Lett., 35, L20810, doi:10.1029/2008GL035441, 2008.
Konopka, P., Günther, G., Müller, R., dos Santos, F. H. S., Schiller, C., Ravegnani, F., Ulanovsky, A., Schlager, H., Volk, C. M., Viciani, S., Pan, L. L., McKenna, D.-S., and Riese, M. Contribution of mixing to upward transport across the tropical tropopause layer (TTL), Atmos. Chem. Phys., 7, 3285-3308, doi:10.5194/acp-7-3285-2007, 2007.

Konopka, P., Grooß, J.-U., Ploeger, F., and Müller, R.: Annual cycle of horizontal in-mixing into the lower tropical stratosphere, J. Geophys. Res., 114, D19111, doi:10.1029/2009JD011955, 2009.

Konopka, P., Grooß, J. U., Günther, G., Ploeger, F., Pommrich, R., Müller, R., and Livesey, N.: Annual cycle of ozone at and above the tropical tropopause: observations versus simulations with the Chemical Lagrangian Model of the Stratosphere (CLaMS), Atmos. Chem. Phys., 10, 121-132, doi:10.5194/acp-10-121-2010, 2010.

Krämer, M., Schiller, C., Afchine, A., Bauer, R., Gensch, I., Mangold, A., Schlicht, S., Spelten, N., Sitnikov, N., Borrmann, S., de Reus, M., and Spichtinger, P.: Ice supersaturations and cirrus cloud crystal numbers, Atmos. Chem. Phys., 9, 3505-3522, doi:10.5194/acp-9-3505-2009, 2009.

Kremser, S., Wohltmann, I., Rex, M., Langematz, U., Dameris, M., and Kunze, M.: Water vapour transport in the tropical tropopause region in coupled Chemistry-Climate Models and ERA-40 reanalysis data, Atmos. Chem. Phys., 9, 2679-2694, doi:10.5194/acp-9-2679-2009, 2009.

Krüger, K., Tegtmeier, S., and Rex, M.: Long-term climatology of air mass transport through the Tropical Tropopause Layer (TTL) during NH winter, Atmos. Chem. Phys., 8, 813-823, doi:10.5194/acp-8-813-2008, 2008.

Legras, B., Joseph, B., and Lefevre, F.: Vertical diffusivity in the lower stratosphere from Lagrangian back-trajectory reconstructions of ozone profiles, J. Geophys. Res., 108, 4562, doi: 10.1029/2002JD003045, 2003.

Liu, S., Fueglistaler, S., and Haynes, P.: Advection-condensation paradigm for stratospheric water vapor, J. Geophys. Res., 115, D24307, doi:10.1029/2010JD014352, 2010.

McKenna, D. S., Grooß, J.-U., Günther, G., Konopka, P., Müller, R., Carver, G., and Sasano, Y.: A new Chemical Lagrangian Model of the Stratosphere (CLaMS): 2. Formulation of chemistry scheme and initialization, J. Geophys. Res., 107, 4256, doi: 10.1029/2000JD000113, 2002a.

McKenna, D. S., Konopka, P., Grooß, J.-U., Günther, G., Müller R., Spang, R., Offermann, D., and Orsolini, Y.: A new Chemical Lagrangian Model of the Stratosphere (CLaMS): 1. Formulation of advection and mixing, J. Geophys. Res., 107, 4309, doi:10. 1029/2000JD000114, 2002b.

Meier, R. R., Anderson, D. E., J., and Nicolet, M.: Radiation Field in the Troposphere and Stratosphere from 240-1000 nm -I: General Analysis, Planet Space Sci, 30, 923-933, 1982.

Monge-Sanz, B. M., Chipperfield, M. P., Simmons, A. J., and Uppala, S. M.: Mean age of air and transport in a CTM: Comparison of different ECMWF analyses, Geophys. Res. Lett., 34, L04801, doi:10.1029/2006GL028515, 2007.

Mote, P. W., Rosenlof, K. H., McIntyre, M. E., Carr, E. S., Gille, J. G., Holton, J. R., Kinnersley, J. S., Pumphrey, H. C., Russell III, J. M., and Waters, J. W.: An atmospheric tape recorder: The imprint of tropical tropopause temperatures on stratospheric water vapor, J. Geophys. Res., 101, 3989-4006, 1996. 
Mote, P. W., Dunkerton, T. J., McIntyre, M. E., Ray, E. A., Haynes, P. H., and Russell III, J. M.: Vertical velocity, vertical diffusion, and dilution by midlatitude air in the tropical lower stratosphere, J. Geophys. Res., 103, 8651-8666, 1998.

Nash, E. R., Newman, P. A., Rosenfield, J. E., and Schoeberl, M. R.: An objective determination of the polar vortex using Ertel's potential vorticity, J. Geophys. Res., 101, 9471-9478, 1996.

Osterman, G. B., Salawitch, R. J., Sen, B., Toon, G. C., Stachnik, R. A., Pickett, H. M., Margitan, J. J., and Peterson, D. B.: Balloon-borne measurements of stratospheric radicals and their precursors: Implications for the production and loss of ozone, Geophys. Res. Lett., 24, 1107-1110, doi:10.1029/97GL00921, 1997.

Pisso, I. and Legras, B.: Turbulent vertical diffusivity in the sub-tropical stratosphere, Atmos. Chem. Phys., 8, 697-707, doi:10.5194/acp-8-697-2008, 2008.

Pisso, I., Marecal, V., Legras, B., and Berthet, G.: Sensitivity of ensemble Lagrangian reconstructions to assimilated wind time step resolution, Atmos. Chem. Phys., 10, 3155-3162, doi:10.5194/acp-10-3155-2010, 2010.

Ploeger, F., Konopka, P., Günther, G., Grooß, J.-U., and Müller, R.: Impact of the vertical velocity scheme on modeling transport in the tropical tropopause layer, J. Geophys. Res., 115, D03301, doi:10.1029/2009JD012023, 2010.

Randel, W. J., Park, M., Wu, F., and Livesey, N.: A large annual cycle in ozone above the tropical tropopause linked to the BrewerDobson circulation, J. Atmos. Sci., 64, 4479-4488, 2007.

Russell, J. M., Gordley, L. L., Park, J. H., Drayson, S. R., Tuck, A. F., Harries, J. E., Cicerone, R. J., Crutzen, P. J., and Frederick, J. E.: The Halogen Occultation Experiment, J. Geophys. Res., 98, 10777-10797, 1993.

Schiller, C., Grooß, J.-U., Konopka, P., Ploeger, F., dos Santos, F. H. S., and Spelten, N.: Hydration and dehydration at the tropical tropopause, Atmos. Chem. Phys., 9, 9647-9660, doi:10.5194/acp-9-9647-2009, 2009.

Schoeberl, M. R., Douglass, A. R., Zhu, Z. X., and Pawson, S.: A comparison of the lower stratospheric age spectra derived from a general circulation model and two data assimilation systems, J. Geophys. Res., 108, 4113, doi:10.1029/2002JD002652, 2003.

Sherwood, S. C.: A stratospheric "drain" over the maritime continent, Geophys. Res. Lett., 27, 677-680, 2000.
Simmons, A., Uppala, S., Dee, S., and Kobayashi, S.: ERA-Interim: New ECMWF reanalysis products from 1989 onwards, ECMWF Newsletter, 110, 25-35, 2006.

Sparling, L. C., Kettleborough, J. A., Haynes, P. H., McIntyre, M. E., Rosenfield, J. E., Schoeberl, M. R., and Newman, P. A.: Diabatic cross-isentropic dispersion in the lower stratosphere, J. Geophys. Res., 102, 25817-25829, 1997.

Thompson, A., Witte, J. C., Jacquelyn, C., Smit, H. G. J., Oltmans, S. J., Johnson, B. J., Kirchhoff, V. W. J. H., and Schmidlin, F. J.: Southern Hemisphere Additional Ozonesondes (SHADOZ) 1998-2004 tropical ozone climatology: 3. Instrumentation, station-to-station variability, and evaluation with simulated flight profiles, J. Geophys. Res., 112, 3304, doi: 10.1029/2005JD007042, 2007.

Ulanosvky, A. E., Yushkov, V. A., Sitnikov, N. M., and Ravegnani, F.: The FOZAN-II fast-response chemiluminescent airborne ozone analyzer, Instrum. Exp. Tech., 44, 249-256, 2001.

Uppala, S., Dee, S., Kobayashi, S., Berrisford, P., and Simmons, A.: Towards a climate data assimilation system: status update of ERA-Interim, ECMWF Newsletter, 115, 12-18, 2008.

Waugh, D. W. and Hall, T. M.: Age of stratospheric air: Theory, observations, and models, Rev. Geophys., 40, 1-27, 2002.

Wennberg, P. O., F., H. T., Jaegle, L., Jacob, D. J., Hintsa, E. J., Lanzendorf, E. J., Anderson, J. G., Gao, R. S., Keim, E. R., Donnelly, S. G., Del Negro, L. A., Fahey, D. W., McKeen, S. A., Salawitch, R. J., Webster, C. R., May, R. D., Herman, R. L., Proffitt, M. H., Margitan, J. J., Atlas, E. L., Schauffler, S. M., Flocke, F., McElroy, C. T., and Bui, T. P.: Hydrogen radicals, nitrogen radicals, and the production of $\mathrm{O}_{3}$ in the upper troposphere, Science, 266, 49-53, 1998.

Wohltmann, I. and Rex, M.: Improvement of vertical and residual velocities in pressure or hybrid sigma-pressure coordinates in analysis data in the stratosphere, Atmos. Chem. Phys., 8, 265272, doi:10.5194/acp-8-265-2008, 2008.

Zöger, M., Schiller, C., and Eicke, N.: Fast in situ hygrometers: A new family of balloonborne and airborne Lyman- $\alpha$ photofragment fluorescence hygrometers, J. Geophys. Res., 104, 18071816, 1999. 